Bulletin of Pharmaceutical Sciences
Assiut University
Website: http://bpsa.journals.ekb.eg/
e-mail: bullpharm@aun.edu.eg

\title{
INFLUENCE OF CELLULOSE AND ACETATE-BASED POLYMERS ON THE RELEASE OF CIPROFLOXACIN HCL FROM EXTENDED RELEASE MATRIX TABLETS PREPARED BY DIRECT COMPRESSION TECHNIQUE
}

Rida Khalid ${ }^{1}$, Muhammad Iqbal Nasiri ${ }^{2 *}$, Humera Sarwar ${ }^{1}$, Riffat Yasmin ${ }^{3}$, Kamran Zaheer ${ }^{1}$, Sohail Anwer ${ }^{1}$ and Anab Fatima ${ }^{3}$

${ }^{1}$ Department of Pharmaceutics, Faculty of Pharmacy, Hamdard University, Karachi, Pakistan

${ }^{2}$ Department of Pharmaceutics, Hamdard Institute of Pharmaceutical Sciences, Hamdard University, Islamabad, Pakistan

${ }^{3}$ Department of Pharmaceutics, Dow College of Pharmacy, Dow University of Health Sciences, Karachi, Pakistan

\begin{abstract}
The objectives of the current study were to investigate the influence of different types and concentration of polymers on release of ciprofloxacin $\mathrm{HCl}$ as well as to formulate an extended release tablets of ciprofloxacin hydrochloride by direct compression method. Twelve formulations (F1-F12) were manually designed using different proportions (10-30\%) of Hydroxypropyl methylcellulose (HPMC), Ethylcellulose (EC) and Kollidon SR polymers. Avicel PH101, talc and magnesium stearate were used in a constant quantity of $2 \%$ in all the formulations. Multiple point dissolution was carried out in different media. Dissolution profiles indicated that formulations F1, F4, F8 and F11, extended the drug release up to 12 hrs, while, other formulations failed to retard the drug release up to desired period. DDSolver software was used to analyze the dissolution profile data for drug release kinetics such as first order, Zero-order, Korsmeyer-Peppas and Higuchi models. Drug polymers compatibility was assessed using Fourier Transformed Infrared (FTIR) spectroscopy. Selected formulations were placed in the stability chamber at accelerated temperature $\left(40 \pm 2^{\circ} \mathrm{C}\right.$ and $\left.\mathrm{RH} 75 \pm 5 \%\right)$ for six months and re-evaluated after 3 and 6 months as per ICH guidelines. The present study accomplished that ethylcellulose alone or in combination with HPMC was found to be an excellent rate controlling agent for ciprofloxacin and may be used successfully to develop extended release tablet formulations.
\end{abstract}

\section{INTRODUCTION}

From the past few years, an extended release (ER) formulation become most efficient parameter for pharmaceutical manufacturer as it can enhance or improve the physiological parameters of the drugs which lead to reduction in adverse effect as well as enhance the compliance of patient ${ }^{1}$. As compared to conventional dosage form, an ER dosage form can decreased dose frequency up to 2 folds $^{2}$ which leads to decrease in toxicity and enhancement in therapeutic effects of $\mathrm{drug}^{3}$.
Modified release drug delivery systems are designed to control the release of drug from the dosage forms. The release of drug should be at desired rate, predictable and reproducible from these systems. Different approaches and methods have been employed which basically work on the same principle of slowing the rate of dissolution or drug release from the dosage forms ${ }^{4}$. In order to avert, repeated administration of unit dosage forms, extended release formulations have been produced to maintain the therapeutic level of drug in the plasma and to avoid toxic concentration.

Received in 15/1/2020 \& Accepted in 22/2/2020 
Therefore, to overcome fluctuation in plasma drug levels and to reduce frequency of administration, various formulations have been designed to control the therapeutic plasma drug concentrations over extended period of time ${ }^{5}$. Extended release formulations of short half-life drugs are better option for the long-term clinical management of chronically ill patients $^{6 \& 7}$. Polymer play an important role in the drug release and by different mechanism polymers control the drug release and bioavailability of drug at the site of action ${ }^{8}$.

Hydroxypropyl methyl cellulose (HPMC) and cellulose ether are widely used to control release of $\operatorname{drug}^{9 \& 10}$. Use of single hydrophilic polymer is not justified in case of highly watersoluble drugs because it diffuses out rapidly through the water-filled pores of matrix. Hydrophobic polymers glycerides, ethyl cellulose (EC) are used for such drugs ${ }^{11-13}$. The application of HPMC-15 cps as matrix polymer in direct compression technique has been reported earlier ${ }^{14}$. Kollidon SR is one of the recently developed matrices forming agents with plastic behaviour. Chemically, Kollidon SR is polyvinyl acetate and polyvinyl pyrrolidone based matrix retarding agent particularly suitable for the manufacture of $\mathrm{pH}$ independent sustained release matrix tablets ${ }^{15 \& 16}$. When the tablets prepared with Kollidon SR are introduced into gastric or intestinal fluid, the water soluble polyvinylpyrrolidone is leached out to form pores through which the active ingredients slowly diffuse outwards in a controlled and pre-determined fashion. Kollidon SR contains no ionic groups which render them inert to the drug molecule (BASF, 1999).

Ciprofloxacin is a synthetic broadspectrum antibacterial agent belong to the class of quinolone, which inhibits bacterial growth by interfering with DNA gyrase ${ }^{17}$, therefore, convenient, well-tolerated and effective for the treatment of UTIs ${ }^{18}$. It is practically insoluble in aqueous medium at neutral $\mathrm{pH}$, but due to its favorable lipophilicity, ciprofloxacin permeation through the gastrointestinal membrane is expected to be rapid and complete $^{19}$.

The objectives of current research work were (a) to prepare an extended release matrix tablets of Ciprofloxacin $\mathrm{HCl}$ by direct compression technique, (b) to investigate the influence of different types and concentration of matrix polymers on release of drug. To achieve these goals, the tablets were formulated using HPMC, Ethyl cellulose and Kollidon SR. In-vitro drug release rates were determined in different dissolution media $(\mathrm{HCl} \mathrm{pH}$ 1.2, Phosphate buffer $\mathrm{pH} 4.5$ and 6.8 ) at $37 \pm 0.5^{\circ} \mathrm{C}$ for $12 \mathrm{hrs}$. Different kinetic models were also applied to study the drug release kinetics.

\section{MATERIALS AND METHOD}

\section{Materials}

Ciprofloxacin Hydrochloride was gifted by Nabiqasim Industries (Pvt) Ltd, Pakistan.

Hydroxypropyl methylcellulose (HPMCK100M), Ethyl cellulose (EC-7cps), and Triacetin USP/FCC were purchased from Colorcon Limited (Kent, England).Kollidon SR was procured from BASF (Ludwigshafen, Germany). Microcrystalline cellulose (Avicel PH101), Potassium Phosphate Dibasic, Potassium Phosphate Monobasic and Sodium Hydroxide were procured from Sigma-Aldrich. Talc was purchased from the $\mathrm{BDH}$ Laboratories Suppliers, England. OrthoPhosphoric Acid and Hydrochloric Acid 37\% were obtained from Merck Pakistan. All other materials used were of pharmaceutical grades.

\section{Methods \\ Preparation of extended release tablets}

Twelve (12) formulations of ciprofloxacin $\mathrm{HCl}$ were manually designed by using microcrystalline cellulose (MCC; Avicel PH101), HPMC (K100M), EC (10cps), Kollidon SR, talc, and magnesium stearate. All the ingredients were weighed accurately using analytical balance (Panther Bm-320). The amount of ciprofloxacin $\mathrm{HCl}$ in each formulation was kept constant $(500 \mathrm{mg}$ per tablet). Trituration and mixing of all ingredients done by using mortar and pestle and then sieved by using 44 mesh size screen. Then, the mixture was transfer in a polybag to mix thoroughly by adding magnesium stearate and talcum as a lubricant/glidant. Finally, ER matrix tablets were directly compressed by using single punch press (China) and evaluated for in-vitro drug release using different dissolution media. Composition of all the formulations are listed in table 1. 
Table 1: Composition of all tablet formulations.

\begin{tabular}{|c|c|c|c|c|c|c|c|c|c|c|c|c|}
\hline \multirow{2}{*}{ Compositions } & \multicolumn{12}{|c|}{ Formulation codes } \\
\hline & F1 & $\mathrm{F} 2$ & F3 & F4 & F5 & F6 & F7 & F8 & F9 & F10 & F11 & F12 \\
\hline Drug (mg) & 500 & 500 & 500 & 500 & 500 & 500 & 500 & 500 & 500 & 500 & 500 & 500 \\
\hline Avicel - pH-101 (mg) & 184 & 184 & 184 & 94 & 94 & 94 & 184 & 184 & 184 & 94 & 94 & 94 \\
\hline Mg. Stearate (mg) & 18 & 18 & 18 & 18 & 18 & 18 & 18 & 18 & 18 & 18 & 18 & 18 \\
\hline Talc (mg) & 18 & 18 & 18 & 18 & 18 & 18 & 18 & 18 & 18 & 18 & 18 & 18 \\
\hline HPMC - K100M (mg) & 90 & 90 & - & 135 & - & 135 & 180 & - & - & 270 & - & - \\
\hline $\mathrm{EC}-10 \mathrm{cps}(\mathrm{mg})$ & 90 & - & 90 & 135 & 135 & - & - & 180 & - & - & 270 & - \\
\hline Kollidon SR (mg) & - & 90 & 90 & - & 135 & 135 & - & - & 180 & - & - & 270 \\
\hline Total weight per tablet $(\mathrm{mg})$ & 900 & 900 & 900 & 900 & 900 & 900 & 900 & 900 & 900 & 900 & 900 & 900 \\
\hline
\end{tabular}

\section{Evaluation of flow properties of powders blends}

Flow properties of all powder blends (10 g) used in the tablet formulations were determined before direct compression by measuring bulk density, tapped density, Carr's index, Hausner ratio, and angle of repose by using the following equations (USP35-NF30, 2013).

$$
\begin{aligned}
& \text { Bulk density }=\frac{M}{V_{o}} \\
& \text { Tapped density }=\frac{M}{V_{f}} \\
& \text { Carr's Index }=\left(\frac{V_{o}-V_{f}}{V_{o}}\right) \times 100 \\
& \text { Hausner ratio }=\frac{V_{o}}{V_{f}} \\
& \tan (\theta)=\frac{\text { height }}{0.5 \text { base }}
\end{aligned}
$$

Where, $\mathrm{M}$ is the mass of powder samples in $\mathrm{g}$, $\mathrm{V}_{\mathrm{o}}$ is the initial volume of powder in $\mathrm{mL}, \mathrm{V}_{f}$ is the final volume of powder samples after tapping in $\mathrm{mL}$ and $\theta$ is the angle of repose. Powders show excellent flow properties if Carr's index $\leq 10$, Hausner ratio ranges between 1.00-1.11 and angle of repose value lies in between 25-30. When, Carr's index lies in between 11-15, Hausner ratio between 1.121.18 and angle of repose value lies in between 31-35, then the powders shows good flow. Similarly, when, Carr's index lies in between 16-20, Hausner ratio between 1.19-1.25 and angle of repose value lies between 36-40, then the powders shows fair flow. Powder shows poor flow properties if Carr's index 25-31, Hausner ratio ranges between $1.35-1.45$ and angle of repose value lies in between 46-56 (USP35-NF30, 2013).

\section{Evaluation of tablet formulations}

ER ciprofloxacin $\mathrm{HCl}(500 \mathrm{mg})$ matrix tablets formulations were characterized using official $^{20}$ and un-official methods for different pharmaceutical quality parameters including weight Variation, hardness, thickness, friability and assay. Weight variation of all tablet formulations were assessed by using digital balance (Sartorius CP 224S, Germany). Tablets should have enough strength to avoid breaking during handling, coating, filling and transportation etc. Normally, to break a tablet minimum $4 \mathrm{~kg}$ of force is required, which was set as tablet hardness limit and tablets were checked through Erweka hardness tester (TBH 125 , Germany $)^{21}$. The degree of compaction was assessed as thickness test and was checked by using digital Vernier Caliper. The friability test of each formulation was also carried out using friabilator (Erweka, Germany), operated for specified period ( 25 rotation/minute for 4 min). Friability test was performed by taking initial and final weight of 10 tablets and calculated by using the following formula ${ }^{22}$.

$$
\text { Friability }(\%)=\frac{(\text { Initial Weight }- \text { Final Weight })}{\text { Initial Weight }} \times 100
$$

The Acceptance criteria specified by USP for friability test is less than $1 \%$ (considered acceptable). 


\section{Fourier transform infrared spectroscopy (FTIR)}

The interaction between the drug and polymers was assessed by using Fouriertransform infrared (FTIR) spectroscopy (Model \# 5300; Shimadzu, Japan). The FTIR spectra of pure drug (ciprofloxacin $\mathrm{HCl}$ ) and different polymers were recorded over the wavenumber ranging from 12000 to $4000 \mathrm{~cm}^{-1}$, by applying $\mathrm{KBr}$ disc method. Recorded FTIR spectra of all formulations and pure drug were evaluated for any shifting and masking of drug peaks due to presence of excipients.

\section{Assay of ciprofloxacin $\mathrm{HCl}$ tablet formulations}

A reported method was used to analyze the ciprofloxacin content in each tablet formulation by using UV- Spectrophotometer (Hitachi, 2000) at $275 \mathrm{~nm}^{23}$.

\section{In-vitro drug release studies}

The release of drug from the dosage from was assessed under dissolution test by using USP type-II dissolution apparatus (Erweka, Germany), operated at $100 \mathrm{rpm}$ in $900 \mathrm{~mL}$ of $0.1 \mathrm{HCl}$ at $\mathrm{pH}-1.2$ maintained at $37 \pm 0.5^{\circ} \mathrm{C}$. The selected formulations (F1, F4, F8 and F11) were also evaluated in phosphate buffer at $\mathrm{pH}$ 4.5 and 6.8 maintained at same temperature. 5 $\mathrm{ml}$ of the sample was withdrawn at regular intervals of 1, 2, 3, 4, 6, 8, 10 and $12 \mathrm{hrs}$ and replaced with the same volume of pre-warmed $\left(37 \pm 0.5^{\circ} \mathrm{C}\right)$ fresh dissolution medium. The drug content in each sample was analyzed after suitable dilution using UV spectrophotometer method at $276 \mathrm{~nm}^{24}$.

\section{Drug release kinetics}

In order to evaluate the mechanism of drug release from the selected formulations, invitro dissolution profiles data were fitted into different kinetic models including zero order, first-order, Higuchi, and Korsmeyer-Peppas. For this purpose, DD Solver (An MS Excel add-in software) was used.

\section{Stability studies}

The objective of the stability study is to estimate the quality of a drug product, which changes under the influence of temperature, humidity and light over time (WHO, 2009). Four selected formulations (F1, F4, F8 and
F11) were subjected at accelerated temperature of $40^{\circ} \mathrm{C} \pm 2^{\circ} \mathrm{C}$ and relative humidity of $75 \% \pm 5 \%$ for 6 months as per International Conference of Harmonization (ICH) guidelines. In order to verify any possible chemical changes during storage, samples were analyzed at 0,3 and 6 months as indicated by the ICH Guideline (Q1E evaluation for stability data). The shelflife of the tablet formulations was calculated using Minitab software (version 17.1.0), a data analysis tool for studies of drug stability (Fig. 6).

\section{RESULTS AND DISCUSSION}

\begin{abstract}
There are approximately 800 pharmaceutical industries in Pakistan producing quality pharmaceutical products and fulfilling the national requirement. National pharmaceutical industry has grown since the last few years, but there are few pharmaceutical manufacturing units that produce specialized dosage forms, such as a controlled delivery system. The main objective of the controlled release system is to obtain a cost-effective and efficient extended release system to deliver drugs at a constant rate in order to obtain a release of zero orders ${ }^{25}$.
\end{abstract}

\section{Formulation Development}

An extended release ciprofloxacin $\mathrm{HCl}$ tablet were compressed using different hydrophilic and hydrophobic polymers through direct compression technique. Due to its simplicity, cost efficiency and the development of excipients, the direct compression method is widely used in industries. Jivraj, et al., reported the functionality of directly compressible fillers (Jones, 2004). Q. Yihong \& G. Zhang, explained the physicochemical behavior of directly compressible binders and their binding properties $^{26}$.

The effect on drug release by different types of polymers was also evaluated. The ER tablets were prepared using different polymers, like HPMC K100M (100000cps), EC (10cps) and Kollidon SR in the concentrations ranges from $10-30 \%$ as mentioned in table 1 . Avicel PH 101 was used in the range of 10 to $20 \%$ of concentration, while magnesium stearate and talc were used in fixed quantities $(2 \%)$ in each formulation. The use of hydrophilic and hydrophobic polymers is very common to 
obtain a controlled release system ${ }^{27}$. Among hydrophilic polymers, HPMC of different viscosity grade (K4M- 4000cps, K15 M- 15000 cps and K100 M - 100000 cps) and acrylic and methacrylic acid copolymers, such as Eudragit RL, RS and NE, have been widely used as matrix formers for extended release systems by several researchers ${ }^{28}$.

\section{Evaluation of powder blends}

The powder blends were evaluated by calculating the bulk density, tapped density, Hausner's ratio, compressibility index and angle of repose of all the formulations and results are showed in table 2. The powder blends which comply with USP specification are categorized as Fair to Excellent, were chosen for compression and further studies. The formulations which complied with USP standards in terms of flow properties were F1, F4, F5, F8, F9, and F11 (USP35-NF30, 2013).

These parameters were found within the prescribed limits (USP, 2013), and no considerable difference was observed between plain (without polymer), EC (7 cps) and HPMC of different viscosity grade (K4M, K15M, and
K100M) pellets. The percent content of ciprofloxacin $\mathrm{HCl}$ in each formulation (F1F15) was found within the prescribed limit in the range of 96.12-102.4\% showing uniformity of drug content, as given in table 3 .

\section{Evaluation of tablet formulations}

Table 3 shows the results of weight variation test of all 12 formulations of ciprofloxacin $\mathrm{HCl}$ tablets. The results were found within the described USP specification of $\pm 5 \%$ (USP35-NF30, 2013). Hardness of all formulations were found satisfactory and the values were observed to be $6.00-7.67 \mathrm{~kg}$ as shown in table 3. Similar results for hardness test were also reported by Hussain et $a .^{29}$. The average thickness of all formulations was observed in the ranges of 7.22-8.194 mm. The results of friability test of formulations $\mathrm{F} 1, \mathrm{~F} 2$, F4, F5, F8, and F11 were found within the USP specification of NMT $1 \%$, whereas, formulations F3, F6, F7, F9, F10, and F12 were found out of the limits $(>1 \%)$ as mentioned in table 3. Mu'az et al., also reported friability results of NMT $1 \%$ for ciprofloxacin tablets ${ }^{30}$.

Table 2: Micromeritic characterization of powder blends of all formulations.

\begin{tabular}{|c|c|c|c|c|c|c|}
\hline $\begin{array}{c}\text { Formulation } \\
\text { Code }\end{array}$ & $\begin{array}{c}\text { Bulk } \\
\text { Density } \\
\left(\mathrm{g} / \mathrm{cm}^{3}\right)\end{array}$ & $\begin{array}{c}\text { Tapped } \\
\text { Density } \\
\left(\mathrm{g} / \mathrm{cm}^{3}\right)\end{array}$ & $\begin{array}{c}\text { Carr's } \\
\text { Index } \\
(\%)\end{array}$ & $\begin{array}{c}\text { Hausner's } \\
\text { Ratio }\end{array}$ & $\begin{array}{c}\text { Angle of } \\
\text { Repose } \\
(\theta)\end{array}$ & $\begin{array}{c}\text { Flow } \\
\text { properties } \\
\text { according to } \\
\text { USP 35 }\end{array}$ \\
\hline F1 & 0.34 & 0.49 & 19.61 & 1.18 & 29.40 & Fair \\
\hline F2 & 0.31 & 0.42 & 26.19 & 1.35 & 26.00 & Poor \\
\hline F3 & 0.29 & 0.39 & 25.64 & 1.34 & 28.00 & Poor \\
\hline F4 & 0.40 & 0.57 & 20.50 & 1.14 & 15.80 & Good \\
\hline F5 & 0.79 & 1.19 & 24.00 & 1.29 & 18.70 & Fair \\
\hline F6 & 0.29 & 0.49 & 40.8 & 1.68 & 48.47 & Very poor \\
\hline F7 & 0.57 & 0.65 & 26.56 & 1.30 & 26.54 & Poor \\
\hline F8 & 0.45 & 0.54 & 20.22 & 1.18 & 23.45 & Good \\
\hline F9 & 0.55 & 0.61 & 18.45 & 1.14 & 21.43 & Good \\
\hline F10 & 0.40 & 0.56 & 27.04 & 1.36 & 27.11 & Poor \\
\hline F11 & 0.59 & 0.66 & 15.76 & 1.12 & 20.65 & Excellent \\
\hline F12 & 0.36 & 0.49 & 30.23 & 1.38 & 27.91 & Poor \\
\hline
\end{tabular}


Table 3: Evaluation of all tablet formulations.

\begin{tabular}{|c|c|c|c|c|c|}
\hline \multirow{2}{*}{ Formulations } & \multicolumn{4}{|c|}{ Physical Evaluation } & \multirow{2}{*}{$\begin{array}{c}\text { Chemical } \\
\text { Evaluation }\end{array}$} \\
\hline & $\begin{array}{l}\text { Weight variation }{ }^{*} \\
(\mathrm{mg})\end{array}$ & $\begin{array}{l}\text { Hardness } \\
\quad(\mathrm{Kg})\end{array}$ & $\begin{array}{l}\text { Thickness }{ }^{* *} \\
\text { (mm) }\end{array}$ & $\begin{array}{l}\text { Friability }{ }^{* * *} \\
(\%)\end{array}$ & \\
\hline F1 & $893.6 \pm 7.9$ & $6.33 \pm 0.53$ & $7.89 \pm 0.01$ & 0.87 & 99.19 \\
\hline $\mathrm{F} 2$ & $893.3 \pm 6.7$ & $6.33 \pm 0.57$ & $8.15 \pm 0.01$ & 0.90 & 100.22 \\
\hline F3 & $892.9 \pm 7.7$ & $6.33 \pm 0.52$ & $8.21 \pm 0.02$ & 1.08 & 99.26 \\
\hline $\mathrm{F} 4$ & $892.9 \pm 6.9$ & $6.00 \pm 0.79$ & $7.75 \pm 0.29$ & 0.71 & 100.38 \\
\hline F5 & $894.2 \pm 4.9$ & $7.67 \pm 0.52$ & $8.16 \pm 0.09$ & 0.68 & 100.04 \\
\hline F6 & $892.8 \pm 4.4$ & $7.00 \pm 0.97$ & $7.92 \pm 0.01$ & 1.11 & 99.05 \\
\hline F7 & $892.3 \pm 7.8$ & $7.33 \pm 0.71$ & $7.22 \pm 0.01$ & 1.22 & 99.77 \\
\hline F8 & $892.6 \pm 6.4$ & $7.00 \pm 0.70$ & $8.14 \pm 0.01$ & 0.67 & 101.80 \\
\hline F9 & $891.2 \pm 6.6$ & $6.67 \pm 0.82$ & $8.19 \pm 0.04$ & 1.16 & 100.15 \\
\hline F10 & $892.9 \pm 4.9$ & $6.33 \pm 0.70$ & $8.16 \pm 0.04$ & 1.8 & 100.40 \\
\hline F11 & $893.2 \pm 6.3$ & $6.67 \pm 0.74$ & $8.16 \pm 0.01$ & 0.65 & 99.65 \\
\hline F12 & $893.1 \pm 7.8$ & $7.67 \pm 0.48$ & $8.22 \pm 0.02$ & 1.38 & 99.22 \\
\hline
\end{tabular}

${ }^{*} n=20,{ }^{* *} n=10$

\section{Fourier transform infrared spectroscopy (FTIR)}

To assess any possible interaction between pure ciprofloxacin $\mathrm{HCl}$ with excipients used in the formulations, drug - excipients compatibility studies were carried out using FTIR spectroscopy. The IR absorption spectra of pure ciprofloxacin $\mathrm{HCl}$ (drug) and different excipients were recorded over the wave number ranging from 12000 to $4000 \mathrm{~cm}^{-1}$. The recorded infrared spectra of pure ciprofloxacin $\mathrm{HCl}$ (reference standard) and tablet formulations (sample), indicated that no drug excipients interaction occurred, i.e. no shifting and masking of drug peaks due to presence of excipients as compare to the standard/ reference. FTIR spectra of pure ciprofloxacin $\mathrm{HCl}$ and formulations F1, F2, F3, F7, F8 and F9 are shown in figures $1 \mathrm{a}, 1 \mathrm{~b}, 1 \mathrm{c}, 1 \mathrm{~d}, 1 \mathrm{e}, 1 \mathrm{f}$ and $1 \mathrm{~g}$, respectively. Reddy \& Navaneetha also reported that there was no change in peaks of admixture compared with drug which indicates that the drug and excipients are compatible ${ }^{31}$.

\section{Assay of ciprofloxacin tablets}

The ciprofloxacin $\mathrm{HCl}$ content in each tablet formulation was carried out by using UV -spectrophotometric method, reported by Naveed and Waheed ${ }^{32}$. The mean percentage assay of all ciprofloxacin tablet formulations were found in the range of $99.05-101.80 \%$, as indicated in table 3. All the results were found within the pharmacopoeial limits of $90-110 \%$ (USP35-NF30, 2013).

\section{In-vitro drug release studies}

Figure 2 shows, in-vitro drug release profiles of all formulations which were conducted in acidic buffer ( $\mathrm{pH}-1.2)$, using a reported method ${ }^{24}$. In-vitro drug release profiles of four selected formulations (F1, F4, F8 \& F11) were also conducted in acidic as well as in phosphate buffer of $\mathrm{pH} 4.5$ and 6.8 (See, Figs. 3-5). The samples were withdrawn at an interval of $1,2,4,6,8,10$ and 12 hrs.These four selected formulations, which containing Ethylcellulose (10cps) alone or in combination with HPMC (K100M) in different concentration, prolonged the drug release up to 12 hrs. Formulations (F3, F7 \& F10) containing HPMC alone released the entire drug within 8 hrs. While, other formulations (F3, F6, F9 and F12) containing Kollidon SR alone or in combination with HPMC and EC, released maximum drugs within 1 to $4 \mathrm{hrs}$.

The formulations containing Kollidon SR as polymer, were dissolved completely before the specified time period, therefore, the release of drugs over the desired period of time was not controlled. However, using this polymer in higher percentage ranges might be effective in controlling the drug release for a longer time. 


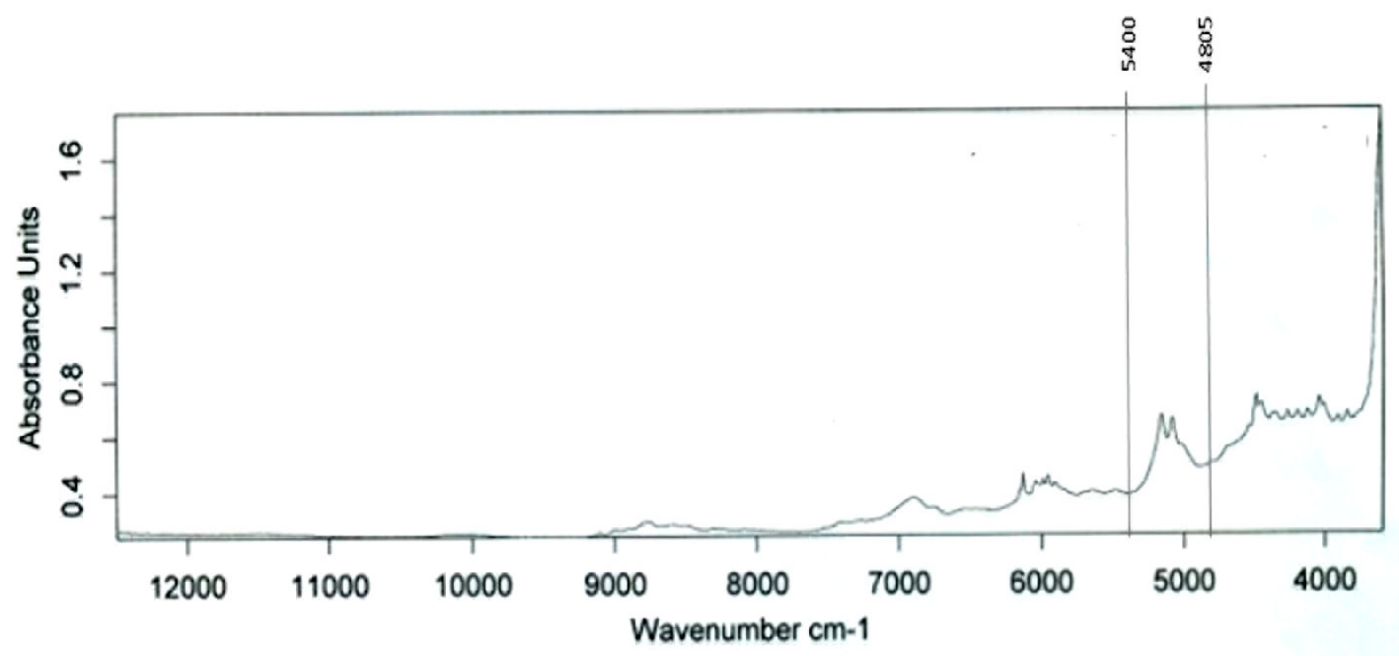

Fig. 1a: FTIR spectra of pure drug.

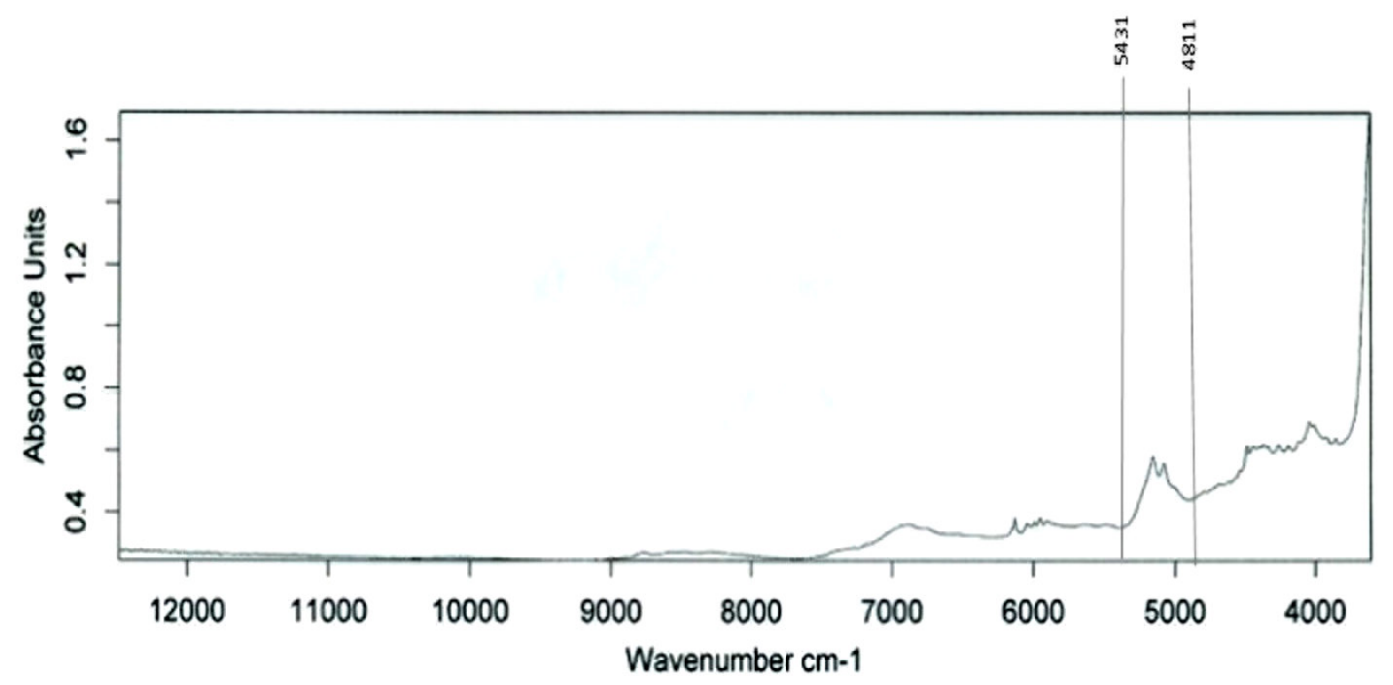

Fig. 1b: FTIR spectra of drug + HPMC + EC.

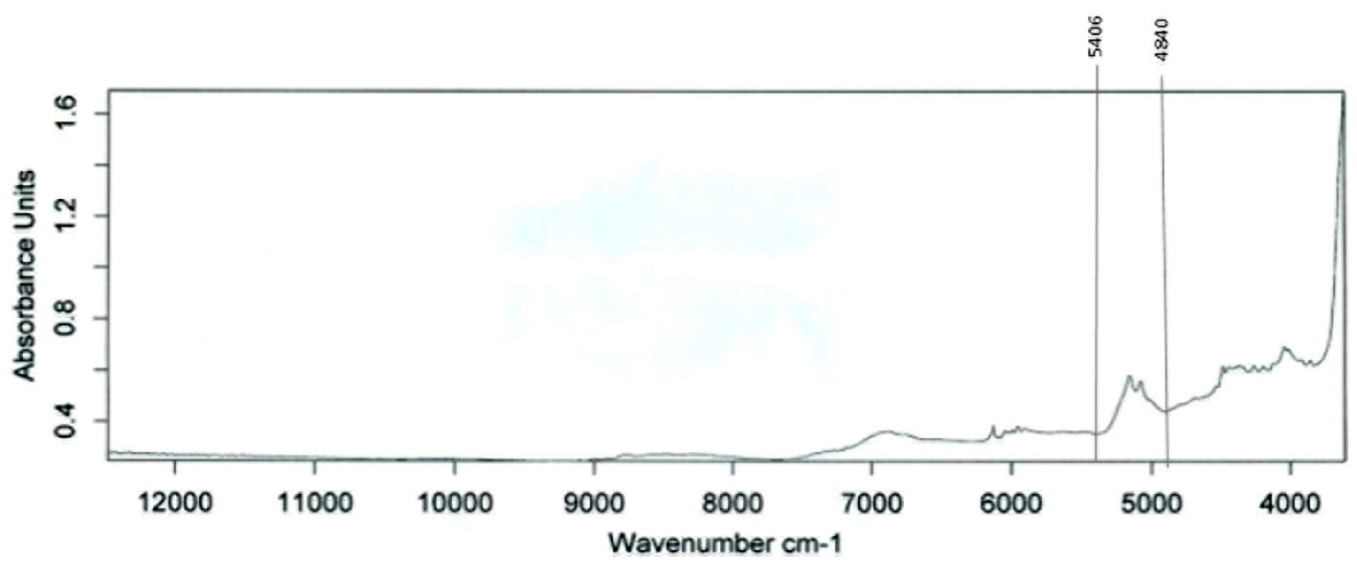

Fig. 1c: FTIR spectra of drug + HPMC + Kollidon SR. 


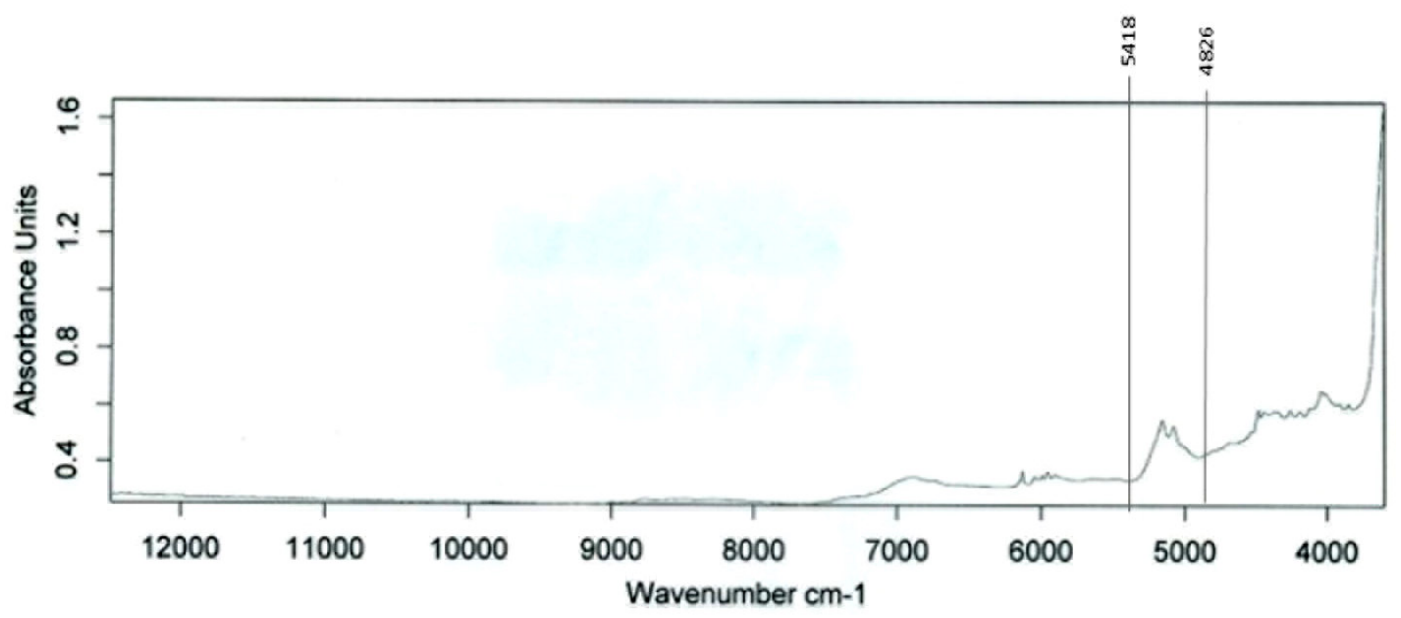

Fig. 1d: FTIR spectra of drug + EC + Kollidon SR.

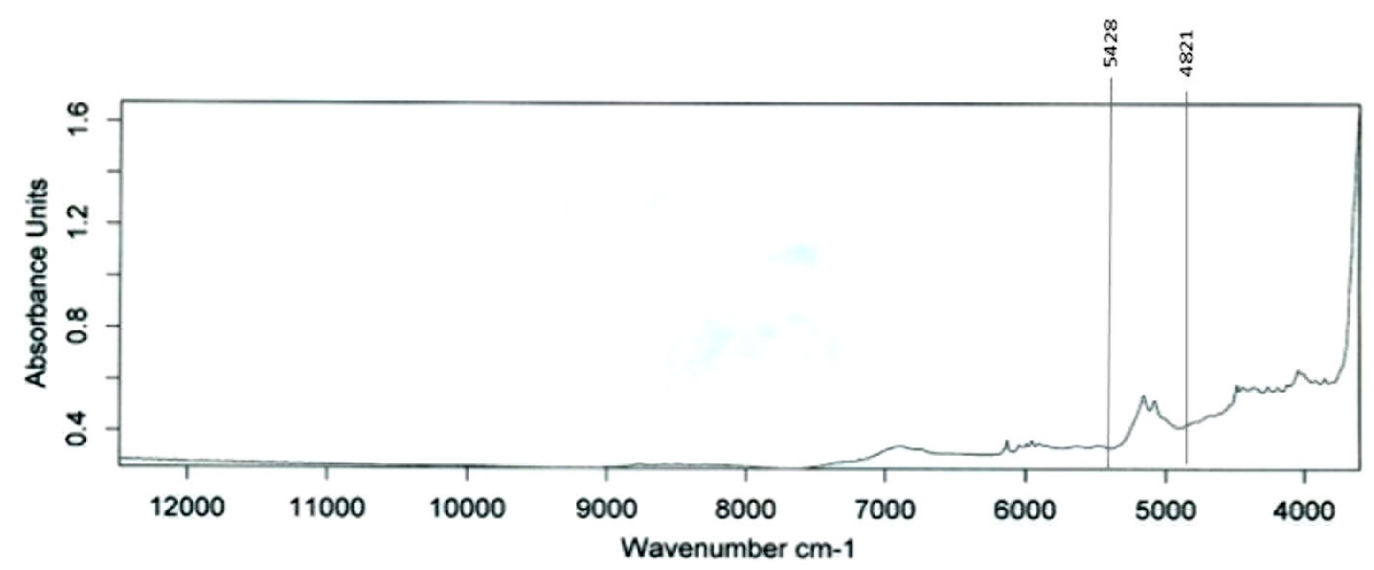

Fig. 1e: FTIR spectra of drug + HPMC.

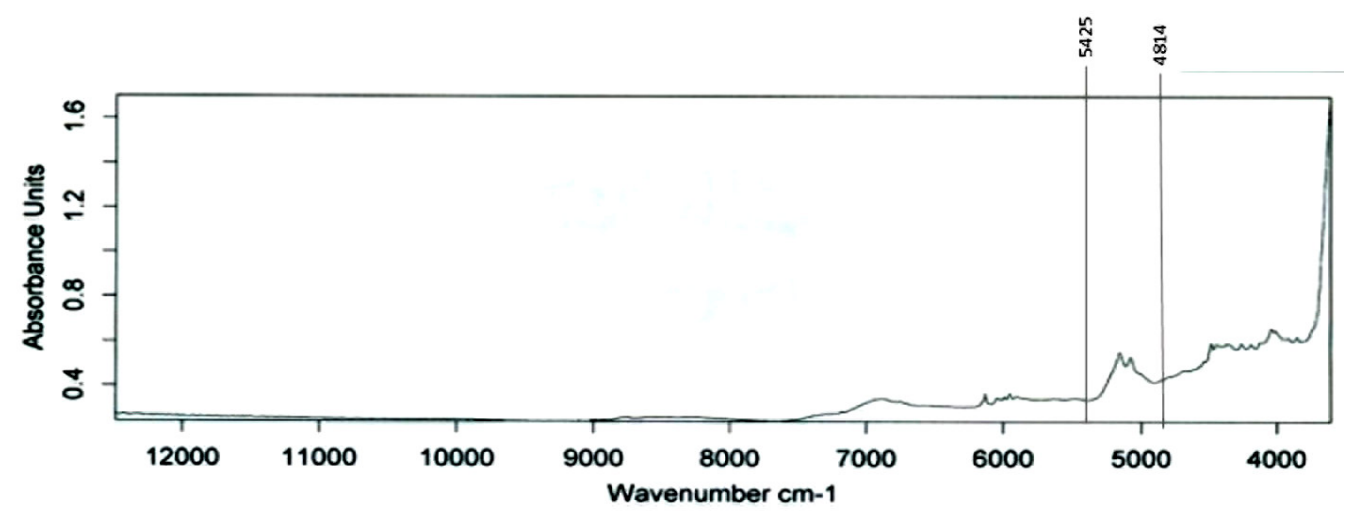

Fig. 1f: FTIR spectra of drug + EC. 


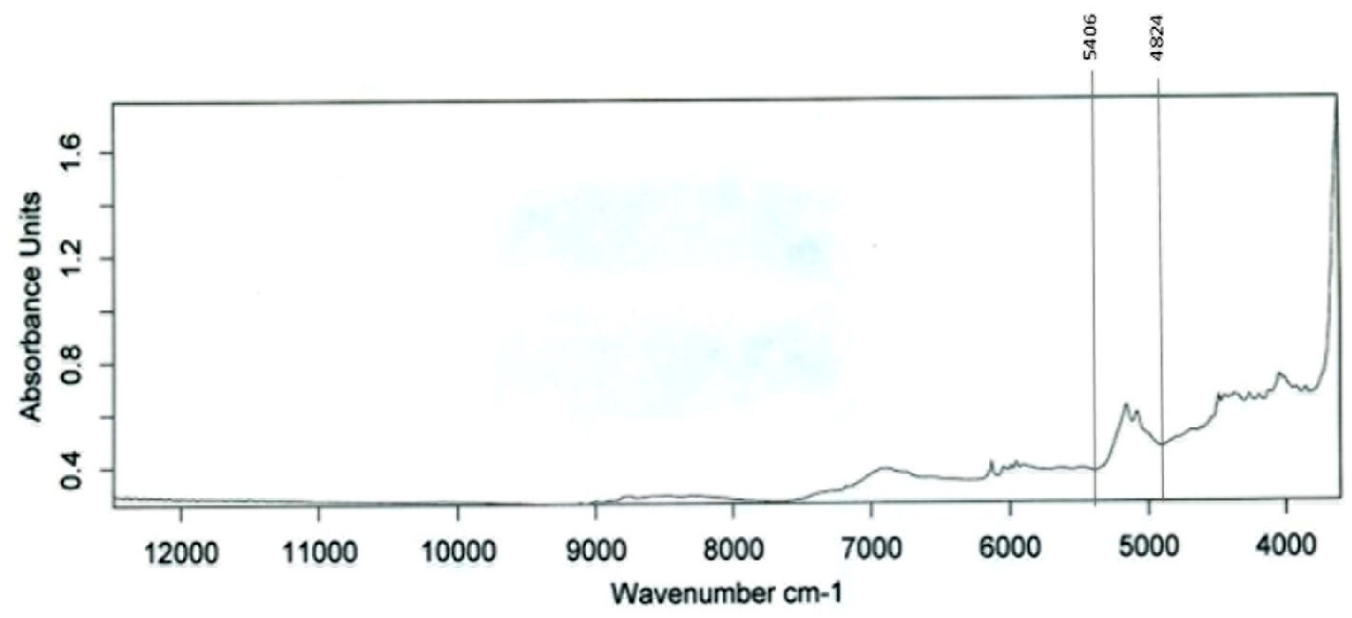

Fig. 1g: FTIR spectra of drug + Kollidon SR.

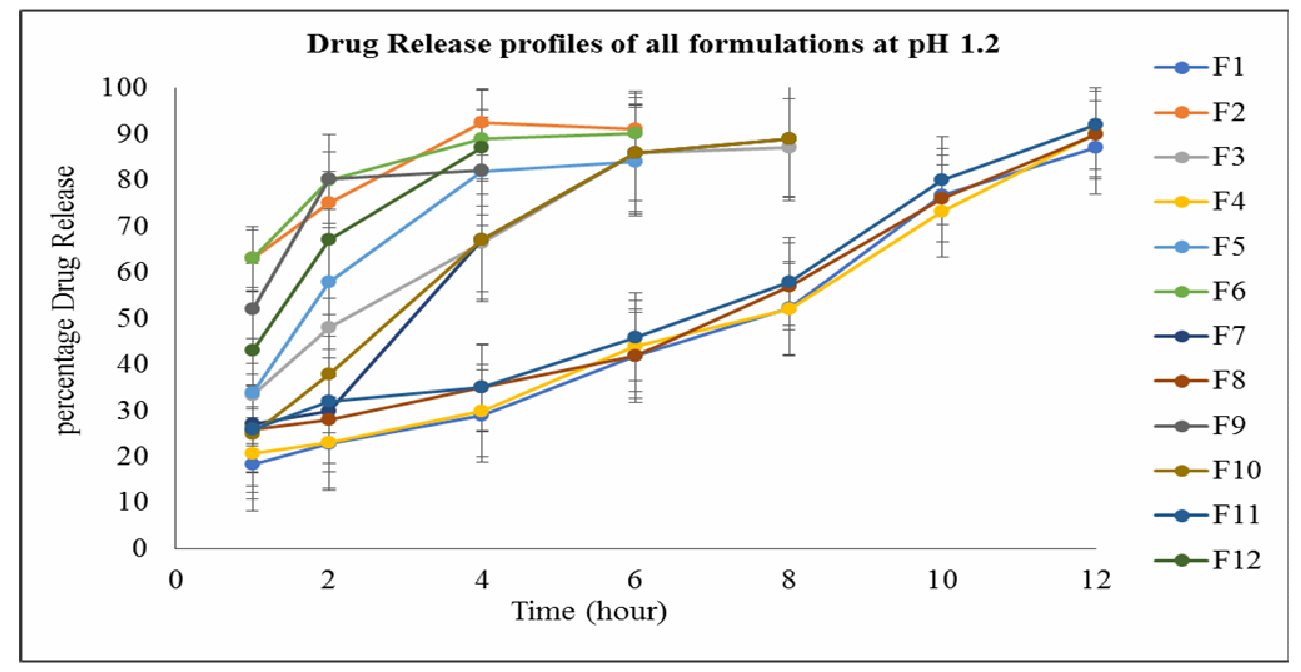

Fig. 2: In-vitro drug release profiles of all formulations at $\mathrm{pH}$ 1.2.

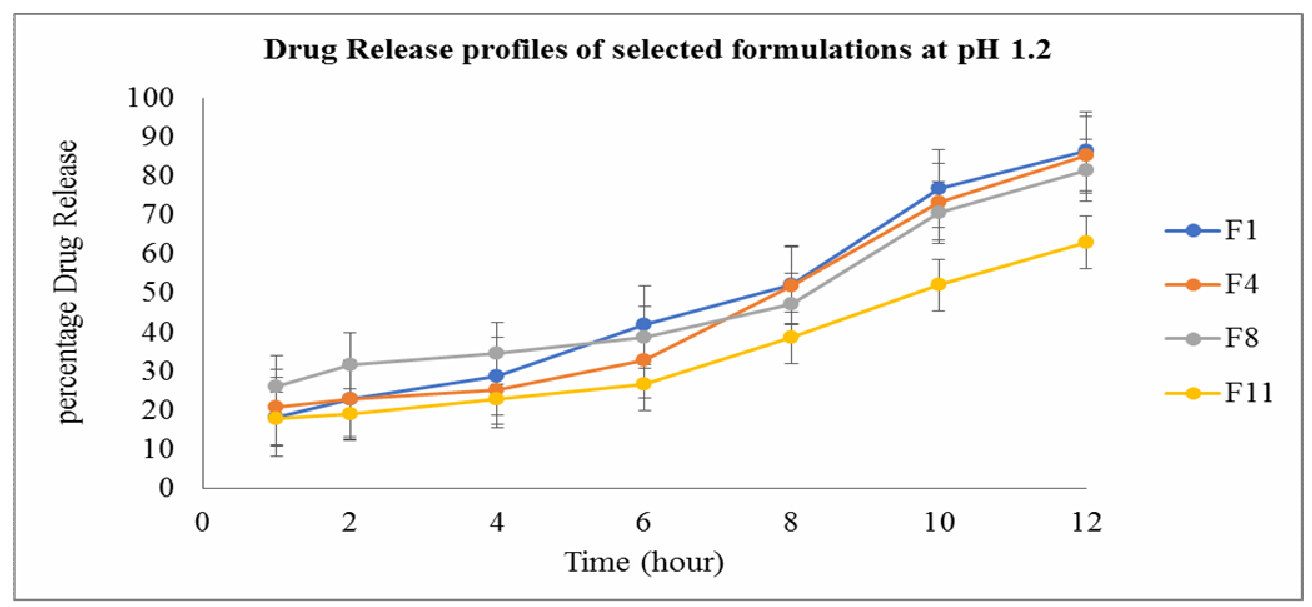

Fig. 3: In-vitro drug release profiles of selected formulations at $\mathrm{pH}$ 1.2. 


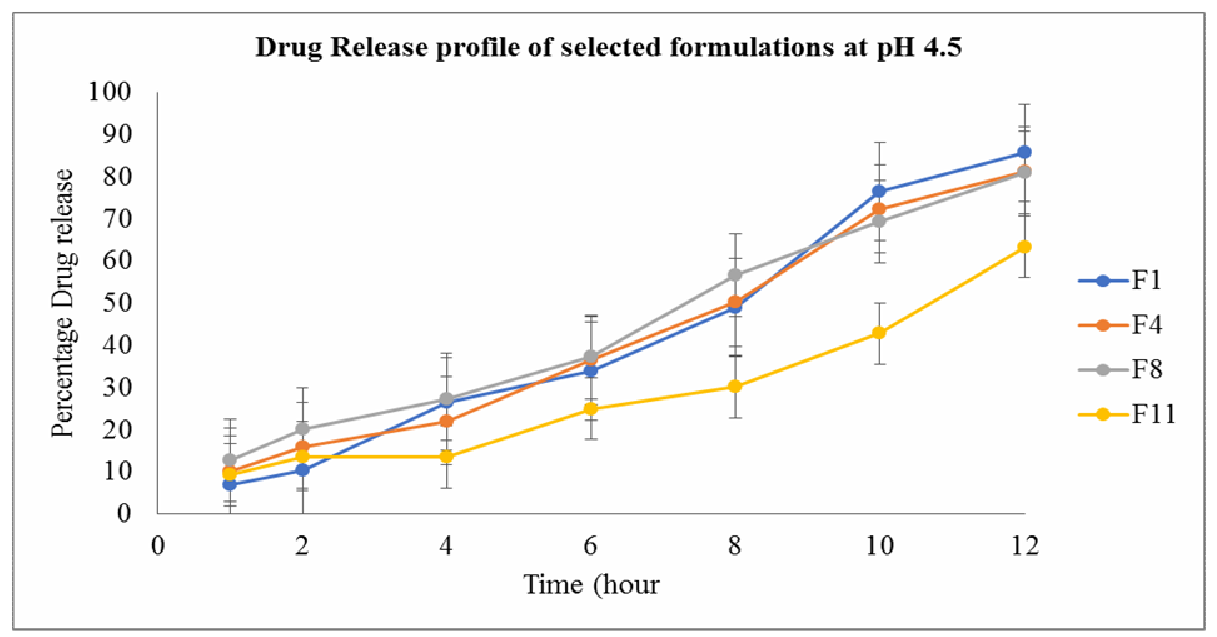

Fig. 4: In-vitro drug release profiles of selected formulations at $\mathrm{pH} 4.5$.

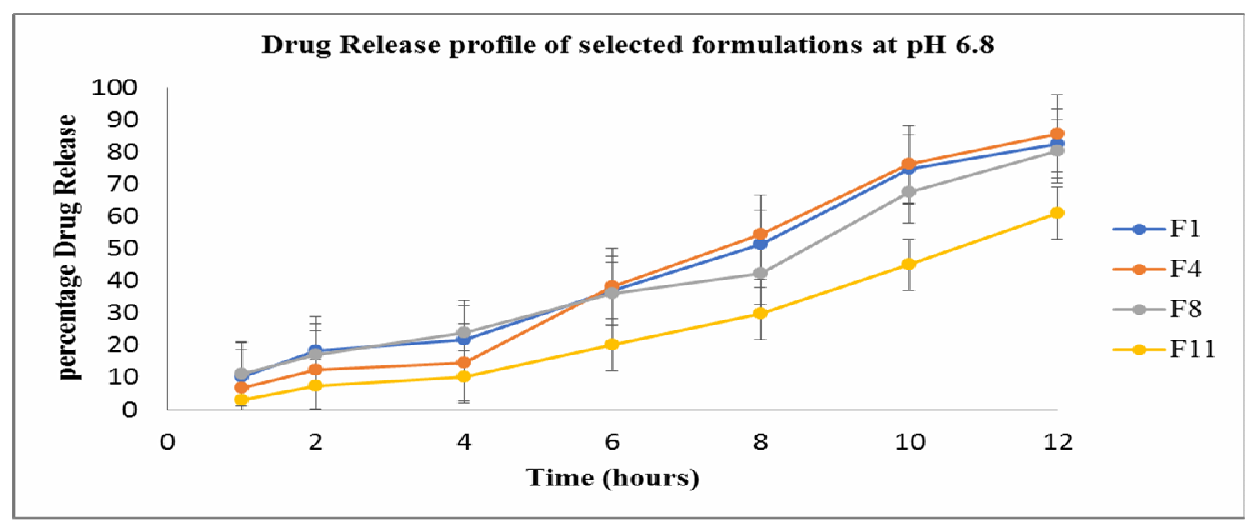

Fig. 5: In-vitro drug release profiles of selected formulations at $\mathrm{pH} 6.8$.

Draganoiu, et, al, in 2003, concluded that Kollidon ${ }^{\circledR} \mathrm{SR}$ is appropriate polymer for $\mathrm{pH}-$ independent extended release matrix tablets ${ }^{26}$. Similarly, formulations containing HPMC $(\mathrm{K} 100 \mathrm{M})$ as rate controlling polymer showed an inadequate release of drug over the desired time period.

Previously, HPMC based sustained release ciprofloxacin tablet formulation were developed and assessed and drug release was found in the range of $80-89 \%$ at $8 \mathrm{~h}^{33}$. Ciprofloxacin as a drug (without salt) is relatively hydrophobic, but also hydrophilic in nature with low solubility or practically insoluble at neutral $\mathrm{pH}^{34}$. However, ciprofloxacin as ciprofloxacin $\mathrm{HCl}$ has more solubility in water(increased up to 2 folds) ${ }^{27}$. HPMC is hydrophilic polymer which is hydrated quickly, thus released maximum drugs within 8 hrs. While, ethylcellulose is hydrophobic polymer retained the ciprofloxacin drug up to $12 \mathrm{hrs}$. Kollidon SR is also a hydrophobic polymer and its sustained release effect depends on drugs' solubility. The ciprofloxacin $\mathrm{HCl}$ is soluble in water and 0.1 $\mathrm{HCl}$ that is why, released the entire drug within 1-4 hrs. To extend the drug release up to 12 hrs, the Kollidon SR should be used in higher quantity i.e. up to $40 \%{ }^{35}$. Similar type of result was also observed with hydrophobic polymer based ciprofloxacin $\mathrm{HCl}$ tablet formulations, which released $97 \%$ of the drug within first 5 $\mathrm{hrs}^{36}$. Another tramadol based formulation containing HPMC and ethylcellulose, showed maximum drug release beyond $12 \mathrm{hrs}^{37}$. 


\section{Drug release kinetics}

Table 4 shows, drug release kinetics of four selected formulations (F1, F4, F8 and F11) at different $\mathrm{pH}$. Different kinetic models, i.e., First Order, Zero Order, Higuchi and Korsmeyer-peppas kinetic models were applied to interpret release kinetics from ciprofloxacin $\mathrm{HCl}$ tablets formulations using DD Solver, a Microsoft Excel add-in program. Mostafavi, et al. also used DD Solver for comparing and modeling the dissolution data profile. The correlation coefficient $\left(\mathrm{r}^{2}\right)$ values obtained from different kinetics models recommended that one of these models may be followed by the formulations. Higher correlation coefficient $\left(r^{2}\right)$ values show that the formulations appear to fit this model better ${ }^{24}$.

F1 and F4 (HPMC + EC) formulations fitted to zero order and Korsmeyer-peppas models with the highest $r^{2}$ values observed as $0.980-0.905$ (zero order) and 0.979-0.888 (Korsmeyer-peppas) at different $\mathrm{pH}(\mathrm{pH} \mathrm{1.2,}$ 4.5 and 6.8). The release exponent $(n=0.865-$ 1.207) also indicated that the combination of diffusion effects and polymer swelling played a role in the release of drugs. While, at $\mathrm{pH} 4.5$ and 6.8, the formulations F8 and F11 (EC) also followed zero order kinetic and Korsmeyerpeppas, where the $r^{2}$ value noted in the ranges of 0.977-0.915, whereas, at $\mathrm{pH} 1.2, \mathrm{~F} 8$ formulation showed this value as 0.692 and F11 as 0.853 , indicating that both formulations were best fitted to Zero order in basic buffer. Similarly, Korsmeyer-peppas $r^{2}$ values of both formulations were observed in the ranges of $0.990-0.941$ at $\mathrm{pH} 4.5$ and 6.8 , however, at 1.2 $\mathrm{pH}, \mathrm{r}^{2}$ values of $\mathrm{F} 8$ and $\mathrm{F} 11$ were 0.804 and 0.865 , respectively. The release exponent values $(\mathrm{n}=1.580-0.592)$ showed that the diffusion and polymer swelling are the main reason of drug release from the tablet. Drug release profile also indicates that, formulations containing both HPMC and EC in combination, gives more optimized formulations as compared to formulation contain EC alone. Merchant et al., estimated the release mechanism of cefpodoxime SR matrix tablets by applying zero order, first order, higuchi, Korsmeyer-peppas and Hixon-Crowell models $^{38}$.

Table 4: Drug release kinetics of all four selected formulations at different $\mathrm{pH}$.

\begin{tabular}{|c|c|c|c|c|c|c|c|c|c|}
\hline \multirow{2}{*}{$\begin{array}{l}\text { Formulation } \\
\text { s code }\end{array}$} & \multicolumn{2}{|c|}{ First Order } & \multicolumn{2}{|c|}{ Zero Order } & \multicolumn{2}{|c|}{ Higuchi } & \multicolumn{3}{|c|}{ Korsmeyer-peppas } \\
\hline & $r^{2}$ & $k_{l}\left(h r^{-1}\right)$ & $r^{2}$ & $K_{0}\left(h r^{-1}\right)$ & $r^{2}$ & $k_{H}\left(h r^{-1 / 2}\right)$ & $r^{2}$ & $\mathrm{n}$ & $k_{k p}\left(h r^{-n}\right)$ \\
\hline \multicolumn{10}{|c|}{ Acidic Buffer (pH 1.2) } \\
\hline F1 & 0.892 & 0.115 & 0.941 & 7.260 & 0.843 & 20.924 & 0.941 & 0.865 & 9.789 \\
\hline $\mathrm{F} 4$ & 0.833 & 0.106 & 0.905 & 6.956 & 0.746 & 19.982 & 0.888 & 0.935 & 8.029 \\
\hline F8 & 0.739 & 0.111 & 0.692 & 6.913 & 0.842 & 20.243 & 0.804 & 0.592 & 16.873 \\
\hline F11 & 0.848 & 0.071 & 0.853 & 5.190 & 0.826 & 15.082 & 0.865 & 0.755 & 8.905 \\
\hline \multicolumn{10}{|c|}{ Phosphate Buffer (pH 4.5) } \\
\hline $\mathrm{F} 1$ & 0.878 & 0.102 & 0.970 & 6.913 & 0.756 & 19.426 & 0.979 & 1.207 & 4.358 \\
\hline $\mathrm{F} 4$ & 0.907 & 0.099 & 0.980 & 6.710 & 0.795 & 19.031 & 0.978 & 1.081 & 5.604 \\
\hline F8 & 0.937 & 0.105 & 0.977 & 6.867 & 0.853 & 19.713 & 0.978 & 0.905 & 8.469 \\
\hline F11 & 0.860 & 0.058 & 0.915 & 4.577 & 0.723 & 12.950 & 0.914 & 1.232 & 2.721 \\
\hline \multicolumn{10}{|c|}{ Phosphate Buffer (pH 6.8) } \\
\hline F1 & 0.897 & 0.103 & 0.972 & 6.853 & 0.793 & 19.460 & 0.969 & 1.068 & 5.886 \\
\hline F4 & 0.863 & 0.103 & 0.961 & 6.970 & 0.735 & 19.500 & 0.977 & 1.261 & 3.889 \\
\hline $\mathrm{F} 8$ & 0.896 & 0.093 & 0.962 & 6.386 & 0.793 & 18.175 & 0.956 & 1.053 & 5.681 \\
\hline F11 & 0.865 & 0.054 & 0.929 & 4.380 & 0.670 & 12.112 & 0.990 & 1.580 & 1.187 \\
\hline
\end{tabular}




\section{Stability studies}

The four selected formulations (F1, F4, F8 and F11) were subjected to accelerated stability studies to assess their physical appearance, drug content, and percentage drug release. All the formulations in rubber-capped amber glass bottles were stored at $40^{\circ} \mathrm{C} / 75 \% \mathrm{RH}$ for 6 months as per ICH guidelines ${ }^{39}$. The percentage content and in-vitro dissolution studies were performed at 0,3 and 6 months and the results showed no change in physical appearance, drug content, and dissolution rates (Fig. 6). Moreover, the stability studies were interpreted by using Minitab (version 17) software. The results showed that all four formulations indicated excellent stability during whole period of study and the shelf life of all formulations were estimated up to 15.774 months. The regression equations/equation for fitted line for each formulation are, \% Assay= 101-0.491 Month.

\section{Conclusion}

Extended release ciprofloxacin $\mathrm{HCl}$ tablets were successfully formulated using different polymers. The formulations containing EC 10cps alone and in combination with HPMC retarded the release of drug up to $12 \mathrm{hrs,}$ while, formulations containing Kollidon SR alone and in combination with HPMC or EC 10cps failed to control the release of drug up to $12 \mathrm{hrs}$ even at high concentration of $30 \%$. FTIR spectra of the drug and formulations showed that there was no interaction among excipients and pure drug. Drug release data of four selected formulations were best explained by Zero order and Korsmeyer-Peppas. Drug release mechanism for all four formulations were swelling and diffusion of polymers. The average shelf-life of all four formulations were 15.774 months, calculated after accelerated stability study. Thus, ethyl cellulose in combination with HPMC can establish an excellent rate controlling agent for ciprofloxacin $\mathrm{HCl}$ drug. Present study concluded that ER formulation of ciprofloxacin $\mathrm{HCl}$ tablets can be successfully prepared by using different polymers i.e. HPMC, EC and Kollidon SR however, for the extended drug release up to $12 \mathrm{hrs}$, combination of HPMC and $\mathrm{EC}$ can be an excellent choice of polymers.

\section{Acknowledgments}

Authors are thankful to M/S Nabiqasim Pharma Private Limited for providing active pharmaceutical ingredient and polymers. Authors also thankful to the Head of Faculty of Pharmacy, Hamdard University Karachi, for providing laboratory facilities, equipment, and their valuable guidance, support, and cooperation.

\section{Conflict of interest statement}

The authors declared no conflict of interests.

\section{Funding}

For this project, no funding was available.

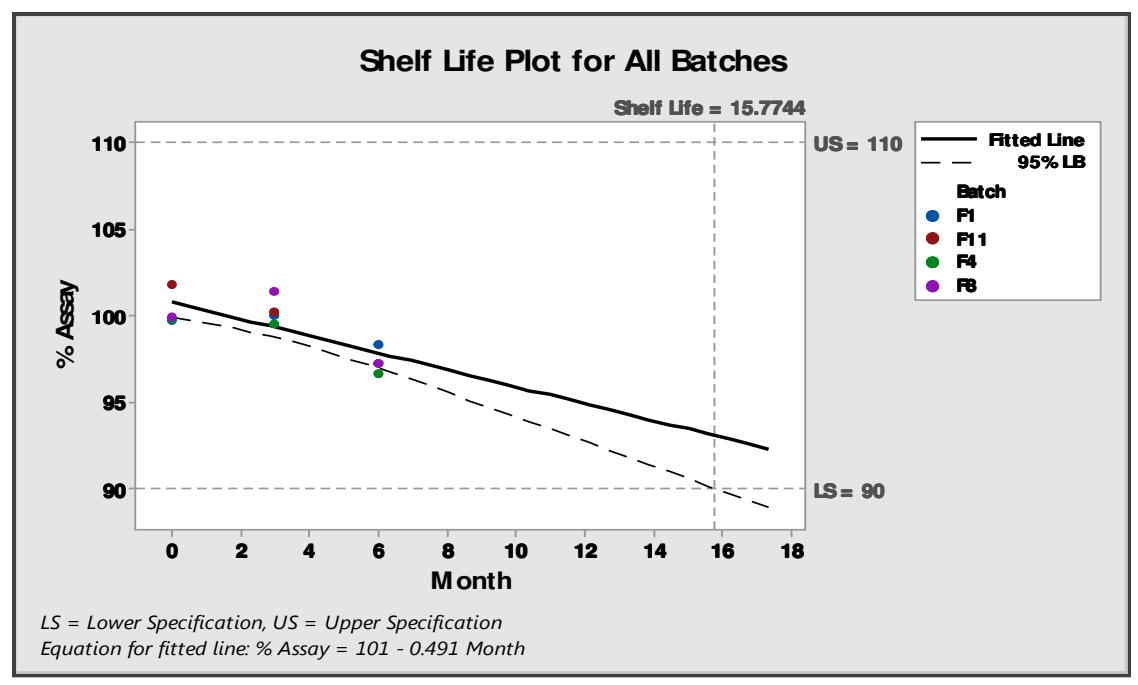

Fig. 6: Stability study (Shelf-Life) plot of all selected formulations. 


\section{REFERENCES}

1- J. Siepmann, R. A. Siegel and M. J. Rathbone, "Fundamentals and Applications of Controlled Release Drug Delivery", $1^{\text {st }}$ Edn., Springer, 2012, p. 127. doi.org/10.1007/978-1-4614-0881-9

2- L. Shargel, B. Andrew and S. Wu-Pong, "Applied Biopharmaceutics \& Pharmacokinetics", $6^{\text {th }}$ Edn., 1999, p. 469, (Appleton \& Lange Stamford, 1999).

3- L. N. Sansom, "Oral extended-release products", Australian Prescriber, 22, 88 (1999).

4- J. E. Devereux, "Gastrointestinal Transit of Multiple Unit Dosage Forms", PhD Dissertation, The School of Pharmacy (University of London), 1987, p. 65.

5- M. Aulton and K. Taylor, "Aulton's Pharmaceutics: The Design and Manufacture of Medicines", $3^{\text {rd }}$ Edn., Elsevier Health Sciences, 2007, p. 484.

6- H. B. Samal, S. Sreenivas, S. Dey and H. Sharma, "Formulation and evalution of sustained release zidovudine matrix tablets", Int. J. Pharm. Pharm. Sci., 3, 32 (2011).

7- L. Lachman, H. A. Lieberman and J. L. Kanig, "The Theory and Practice of Industrial Pharmacy", Lea \& Febiger Philadelphia, 1976, p. 430.

8- H. P. James, R. John, A. Alex and K. Anoop, "Smart polymers for the controlled delivery of drugs - A concise overview", Acta Pharmaceutica Sinica B, 4, 120 (2014).

9- J. Siepmann, H. Kranz, R. Bodmeier and N. Peppas, "HPMC-matrices for controlled drug delivery: A new model combining diffusion, swelling, and dissolution mechanisms and predicting the release kinetics", Pharmaceutical Research, 16, 1748 (1999).

10- T. D. Reynolds, S. H. Gehrke, A. S. Hussain and L. S. Shenouda, "Polymer erosion and drug release characterization of hydroxypropyl hethylcellulose matrices", Journal of Pharmaceutical Sciences, 87, 1115 (1998).

11- N. S. Barakat, I. M. Elbagory and A. S. Almurshedi, "Controlled-release carbamazepine matrix granules and tablets comprising lipophilic and hydrophilic components", Drug Delivery, 16, 57 (2009).

12- S. Kiortsis, K. Kachrimanis, T. Broussali and S. Malamataris, "Drug release from tableted wet granulations comprising cellulosic (HPMC or HPC) and hydrophobic component", European Journal of Pharmaceutics and Biopharmaceutics, 59, 73 (2005).

13- A. Kuksal, A. K. Tiwary, N. K. Jain and S. Jain, "Formulation and in-vitro, in-vivo evaluation of extended-release matrix tablet of zidovudine: Influence of combination of hydrophilic and hydrophobic matrix formers", $\boldsymbol{A A P S}$ Pharmscitech, 7, E1 (2006).

14- J. Bain, S. Tan, D. Ganderton and M. Solomon, "Comparison of the in-vitro release characteristics of a wax matrix and a hydrogel sustained release diclofenac sodium tablet", Drug Development and Industrial Pharmacy, 17, 215 (1991).

15- F. Ruchatz, K. Kolter, S. Wittemer and W. Frauenhofer, "Kollidon SR. A new excipient for sustained release matrices", In: Proc. Int. Symp. Control Release Bioactive Materials, Vol. 26, 1999, p. 6312.

16- E. Draganoiu, M. Andheria and A. Sakr, "Evaluation of the new polyvinylacetate", Pharmazeutische Industrie, 63, 624 (2001).

17- C. C. Sanders, "Ciprofloxacin: In-vitro activity, mechanism of action, and resistance", Reviews of Infectious Diseases, 10, 516 (1988).

18- D. A. Talan, I. W. Klimberg, L. E. Nicolle, J. Song, S. F. Kowalsky and D. A. Church, "Once daily, extended release ciprofloxacin for complicated urinary tract infections and acute uncomplicated pyelonephritis" The Journal of Urology, 171, 734 (2004).

19- G. L. Amidon, H. Lennernäs, V. P. Shah and J. R. Crison, "A theoretical basis for a biopharmaceutic drug classification: The correlation of in-vitro drug product dissolution and in-vivo bioavailability", Pharmaceutical Research, 12, 413 (1995).

20- USP35-NF30. "The United States Pharmacopeial Convention", USA (2013). 
21- N. Mathur, R. Kumar, K. Tiwari, S. Singh and N. Fatima, "Evaluation of quality control parameters on various brands of paracetamol tablet formulation", World $\boldsymbol{J}$. Pharm. Pharm. Sci., 4, 982 (2015).

22- F. Qamar, S. Alam, S. Naveed and H. Ali, "Quality Assessment and Dissolution Profile Comparison Studies on Naproxen Tablets Available in Karachi", RADS Journal of Pharmacy and Pharmaceutical Sciences, 5, 32 (2017).

23- N. Waheed, "Simple Uv Spectrophotometric Assay of Ciprofloxacin", Mintage Journal of Pharmaceutical and Medical Sciences, 10 (2014).

24- A. Mostafavi, J. Emami, J. Varshosaz, N. M. Davies and M. Rezazadeh, "Development of a prolonged-release gastroretentive tablet formulation of ciprofloxacin hydrochloride: Pharmacokinetic characterization in healthy human volunteers", International Journal of Pharmaceutics, 409, 128 (2011).

25- D. L. Wise, "Handbook of Pharmaceutical Controlled Release Technology", $1^{\text {st }}$ Edn., CRC Press, 2000, p. 28.

26- Q. Yihong and G. Zhang, "ControlledRelease Dosage Forms", Handbook of Pharmaceutical Controlled Release Technology, (Wise, D. L. Edt), Marcel Dekker Inc, 2000, p. 465.

27- A. I. Caço, F. Varanda, M. J. Pratas de Melo, A. M. Dias, R. Dohrn and I. M. Marrucho, "Solubility of antibiotics in different solvents. Part II. Nonhydrochloride forms of tetracycline and ciprofloxacin", Industrial \& Engineering Chemistry Research, 47, 8083 (2008).

28- K. Alekseev, E. Blynskaya, N. Tikhonova, V. Alekseev, N. Uvarov and O. Chernova, "Polymers in the formulation of drug dosage forms with modified release", Russian Journal of General Chemistry, 82, 564 (2012).

29- A. Hussain, M. Hanif, M. H. Shoaib, R. I. Yousuf, T. Ali, I. N. Muhammad, L. Hussain, M. Fayyaz and N. Shafi, "Comparative studies of ciprofloxacin 250 mg tablets available in Pakistani market", Lat. Am. J. Pharm., 32, 484 (2013).

30- J. Mu'az, L. Gazali, G. Sadiq and G. Tom, "Comparative in-vitro evaluation of the pharmaceutical and chemical equivalence of multi-source generic ciprofloxacin hydrochloride tablets around Maiduguri metropolitan area", Nigerian Journal of Pharmaceutical Sciences, 8, 102 (2009).

31- B. V. Reddy and K. Navaneetha, "Formulation and characterization of ciprofloxacin Hcl floating tablets", IJPRD, 6, 23 (2014).

32- S. Naveed and N. Waheed, "Simple UV spectrophotometric assay of ciprofloxacin", Mintage J. Pharm. Med. Sci., 3, 10 (2014).

33- S. Basak, K. N. Rao, R. Manavalan and P. R. Rao, "Development and in-vitro evaluation of an oral floating matrix tablet formulation of ciprofloxacin", Indian Journal of Pharmaceutical Sciences, 66, 313 (2004).

34- M. Bajgrowicz, C.-M. Phan, L. N. Subbaraman and L. Jones, "Release of ciprofloxacin and moxifloxacin from daily disposable contact lenses from an in-vitro eye model", Investigative Ophthalmology \& Visual Science, 56, 2234 (2015). doi:10.1167/iovs.15-16379.

35- https://industries.basf.com/bin/bws/ documentDownload.en.8805244119509.

36- H. Nageh, M. Ezzat, M. Ghanim, A. Hassanin and A. A. El-Moneim, "Evaluation of antibacterial activity and drug release behavior of chitosan-based nanofibers (In-vitro study)", $\boldsymbol{U K} \boldsymbol{J}$. Pharm. Biosci., 2, 1 (2014).

37- S. B. Tiwari, T. K. Murthy, M. R. Pai, P. R. Mehta and P. B. Chowdary, "Controlled release formulation of tramadol hydrochloride using hydrophilic and hydrophobic matrix system", AAPS Pharmscitech, 4, 18 (2003).

38- H. A. Merchant, H. M. Shoaib, J. Tazeen and R. I. Yousuf, "Once-daily tablet formulation and in-vitro release evaluation of cefpodoxime using hydroxypropyl methylcellulose: A technical note", ibid., 7, E178 (2006).

39- I.C.H. Guideline, In: "International Conference on Harmonisation of Technical Requirements for Registration of Pharmaceuticals for Human Use", Stability Testing of New Drug Substances and Products, Q1A(R2), 4 version, 2003, p. 9. 


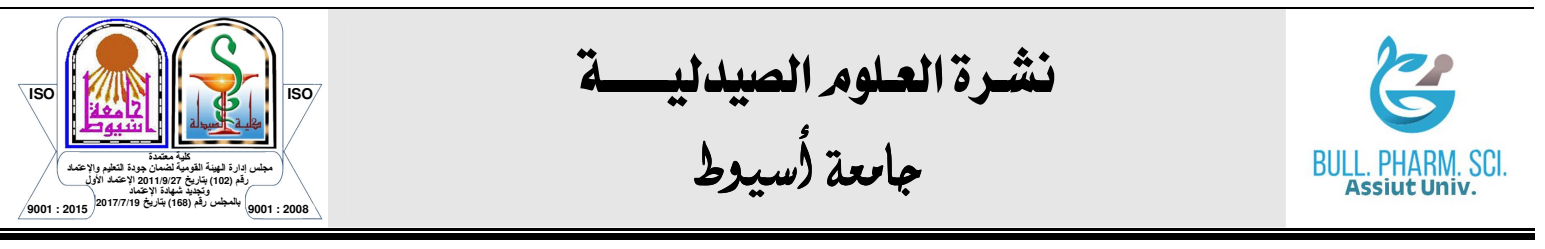

تأثير البوليمرات السليولوزية والخلاتية على انطلاق عقار هيدروكلوريد

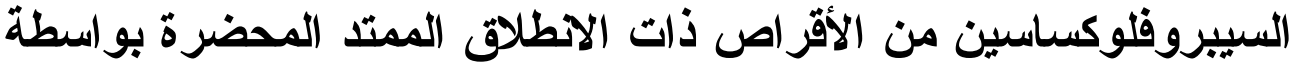

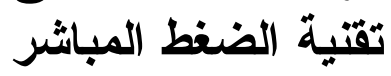

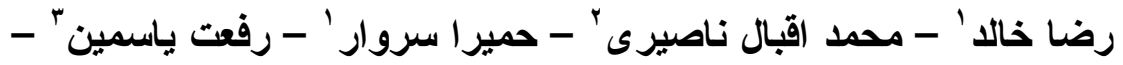

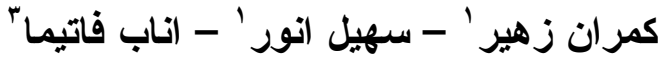

'قسم الصيدلانيات ، كلية الصيدلة ، جامعة حمدارد ، كراتشي ، باكستان

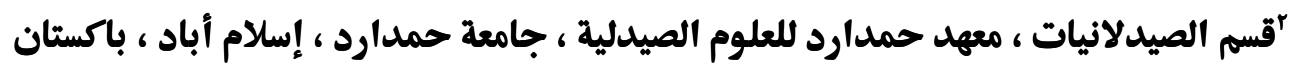

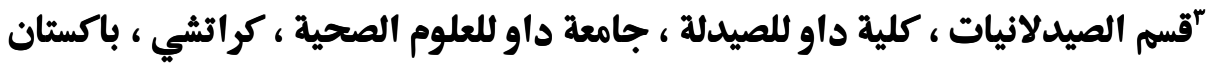

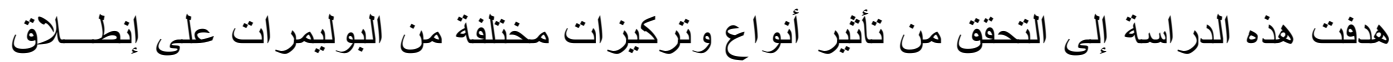

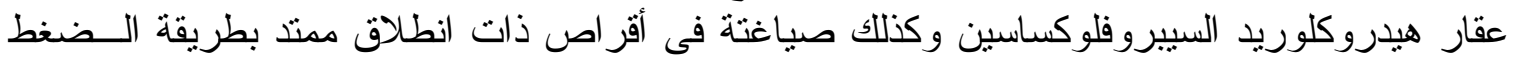

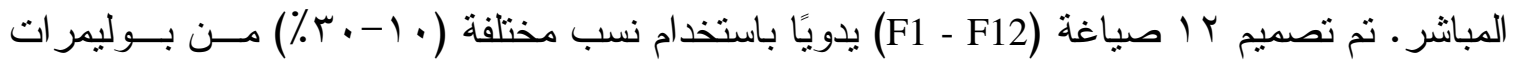

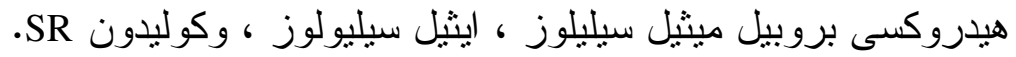

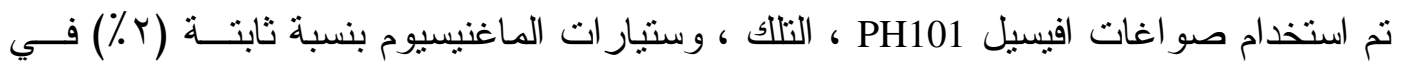

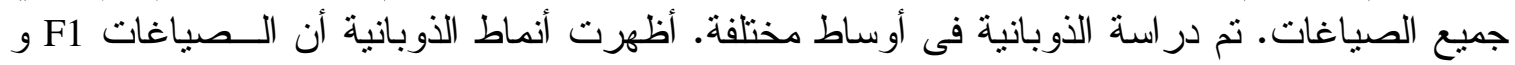

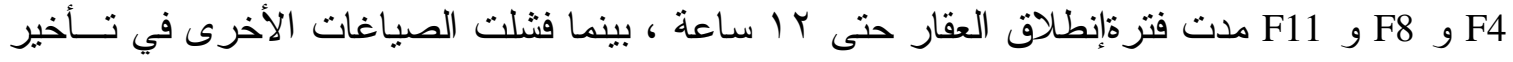
إنطلاق الدو اء حتى الفترة المطلوبة.

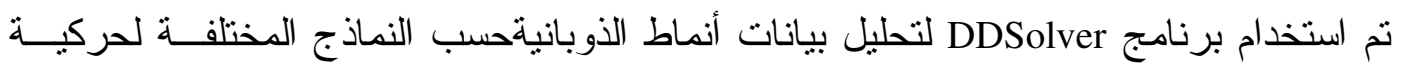
إنطلاق الدواء. وتم تقييم تو افق العقار مع البوليمرات المستخدمة باستخدام التحليل الطيفي بالأشعة تحت

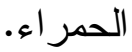

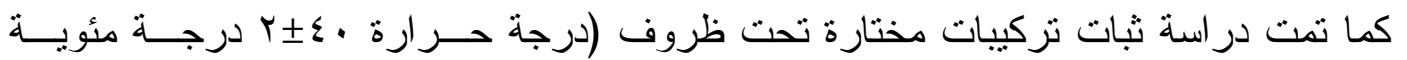

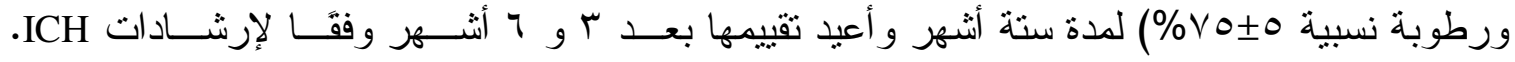

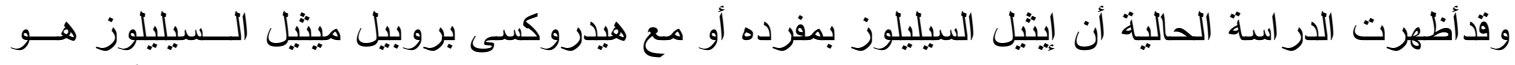

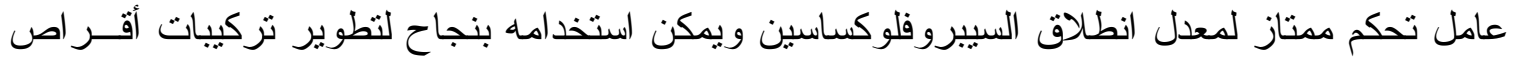
ممندة الإنطلاق. 